\title{
Research Paper: Effects of Flashing Brake Lights on Drivers' Brake Reaction Time and Releasing Accelerator Gas Pedal Time
}

\author{
Mohammad Sadegh Sohrabi ${ }^{*}$ (iD
}

1. Department of Industrial Design, Faculty of Architecture \& Urban Design, Art University of Isfahan, Isfahan, Iran

Citation: Sohrabi MS. Effects of Flashing Brake Lights on Drivers' Brake Reaction Time and Releasing Accelerator Gas Pedal Time. Health in Emergencies and Disasters Quarterly. 2019; 4(4):209-216. http://dx.doi.org/10.32598/hdq.4.4.209

http://dx.doi.org/10.32598/hdq.4.4.209

\section{(i) (5)}

Article info:

Received: 27 Nov 2018

Accepted: 23 Mar 2019

Available Online: $01 \mathrm{Jul} 2019$

\section{Keywords:}

Ergonomics, Automobile driving, Accidents, Traffic

\section{ABSTRACT}

Background: Drivers play a crucial role in accidents. By paying attention to brake lights, a driver may find out about danger and react adequately. Rear-end collision accidents are caused by the driver's inattention or slow reaction. This study aimed to determine the effect of dynamic flashing brake lights $(7 \mathrm{~Hz})$ on drivers' brake reaction time using the driving simulator.

Materials and Methods: This experimental study was done on 46 volunteer drivers (10 females and 36 males). After verification of drivers' vision health by an optometrist (10/10 complete and non-color blindness) and responding to a demographic questionnaire, the participants were subjected to drive for an hour during day and night using a driving simulator system with the standard and dynamic flashing brake lights.

Results: The results indicated that for each 1 year increase in the drivers' age, the brake reaction time decreased $11.585 \mathrm{~ms}$. Women had slower brake reaction time than men $(75.52 \mathrm{~ms})$. No significant relationship was found between the driving condition and brake reaction time. Computer driving gamers had shorter mean reaction time compared with non-game players. The time elapsed since taking a driving license had no significant effect on reaction time. Using flashing brake lights reduced the brake reaction time of drivers $(323.42 \mathrm{~ms} ; \mathrm{P}<0.001)$.

Conclusion: The current research using dynamic flashing brake lights with a flashing frequency of $7 \mathrm{~Hz}$ showed that flashing brake lights significantly reduced the brake reaction time. This reduction was equivalent to $10.78 \mathrm{~m}$ at a speed of about $120 \mathrm{~km} / \mathrm{h}$ or $7.19 \mathrm{~m}$ at $80 \mathrm{~km} / \mathrm{h}$. 


\section{Introduction}

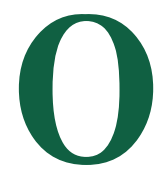

ver 1.2 million people die each year as a result of traffic accidents worldwide, and between 20 and 50 million people suffer from non-fatal injuries. In 2004, car accidents were known as the ninth cause of the global death rate and based on the World Health Organization (WHO) report, this rank will increase to the fifth cause by 2030 [1]. In many regions of the world, the incidence of road traffic injuries is still increasing. Over $90 \%$ of deaths on the world's roads occur in low-income and middle-income countries, which have only $48 \%$ of the world's vehicles $[1,2]$. According to the WHO Global Burden of Disease Project, road traffic accidents caused 1.27 million deaths in 2004. The road traffic injuries exert a considerable economic burden worldwide, especially in developing countries, which are under pressure to provide their developmental needs $[3,4]$. The global financial loss due to road traffic injuries are estimated to be US $\$ 518$ billion and it costs governments between $1 \%$ and $3 \%$ of their gross national product. According to the Legal Medicine Organization of Iran, 23362 trafficrelated deaths were recorded in the 2009-2010 period and 22974 in the 2008-2009 period [5]. Traffic accidents in Iran have become a social problem and are among the significant causes of death [3].

A study in Japan showed that rear-end collision is responsible for $4 \%$ of mortalities and $50 \%$ of damages. In a study to find the underlying reason for such accidents, it was reported that $46 \%$ of them result from the lack of drivers' attention on the front, $24 \%$ from errors in decision making, $14 \%$ from driver's lack of concentration and careless decision making, and 10\% from car failure [6]. Three major factors are involved in each road accident: the car, its mechanical failure, and improper function; the environment, precipitation, road, etc.; and human errors.

The lack of attention toward the front as well as delayed reactions are the main reasons for accidents. Human factors are the leading causes or the determining factors in $90-95 \%$ of all traffic accidents. Human factors refer to the physical, psychological, social, and cultural characteristics of the drivers [4]. Therefore, as a human factor, driver's carelessness and lack of alertness increase the risk of an accident [3, 7-9]. Increasing risk comprehension and reducing the time to react can result in fewer car accidents [10]. The important factors to cause a rear-end collision are the driver's inattention, division of attention, wrong reaction, delay in response, following too closely, and looking around while driving $[11,12]$.
In the 1970s, the third brake light was used to decrease the risk of accidents, which was installed between the existing brake lights. This system was found useful in preventing about 126,000 accidents and also in terms of treatment and extra charges, it saved over $\$ 5$ million [13]. Nowadays, scientists believe that using Emergency Brake Light Display (EBLD) or other attention capturing systems results in a quicker reaction by drivers to the front car's brake [14-16]. In the EBLD system, in addition to the regular brake lights, some other braking lights are used and these signals alert the drivers and shorten their reaction time [17].

Also, the effect of bright lights has been reported on the level of consciousness and sleepiness of people who work at night with special occupations [18]. Prevention of traffic accidents and injuries has been a global concern $[19,20]$. Drivers need to have an acceptable level of physical and mental health to reduce risky road behaviors. Their characteristics are associated with their driving abilities and behaviors [4]. This study aimed at investigating the effect of flashing brake light $(7 \mathrm{~Hz})$ in decreasing drivers' brake reaction time as well as release gas pedal time.

\section{Materials and Methods}

\section{Study participants}

The current study was conducted on 46 volunteer drivers (10 females and 36 males), of whom more than $60 \%$ were taxi drivers. They were informed about the conditions and objectives of the study and provided their informed consent. All participants had the second-grade driver's license of Iran and were examined for their vision (10/10 vision and non-color blindness) [21]. They also filled a demographic questionnaire including age, gender, the time elapsed since taking driver's license, history of driving, and a history of playing computer driving games. Driving experience divides drivers into three groups: novice (driving less than $1000 \mathrm{~km}$ ), beginner (driving between 1000 and 50,000 km), and experienced drivers (driving over $50,000 \mathrm{~km}$ ) [22].

\section{Study instruments}

In the present study, we applied the driving simulator model PR-M3, which has been approved by the Iranian Research Organization for Science and Technology both scientifically and technically. The simulator is a mechatronics software system that assimilates different parts of a car and creates an artificial driving environment using proper software and hardware. It also can record 


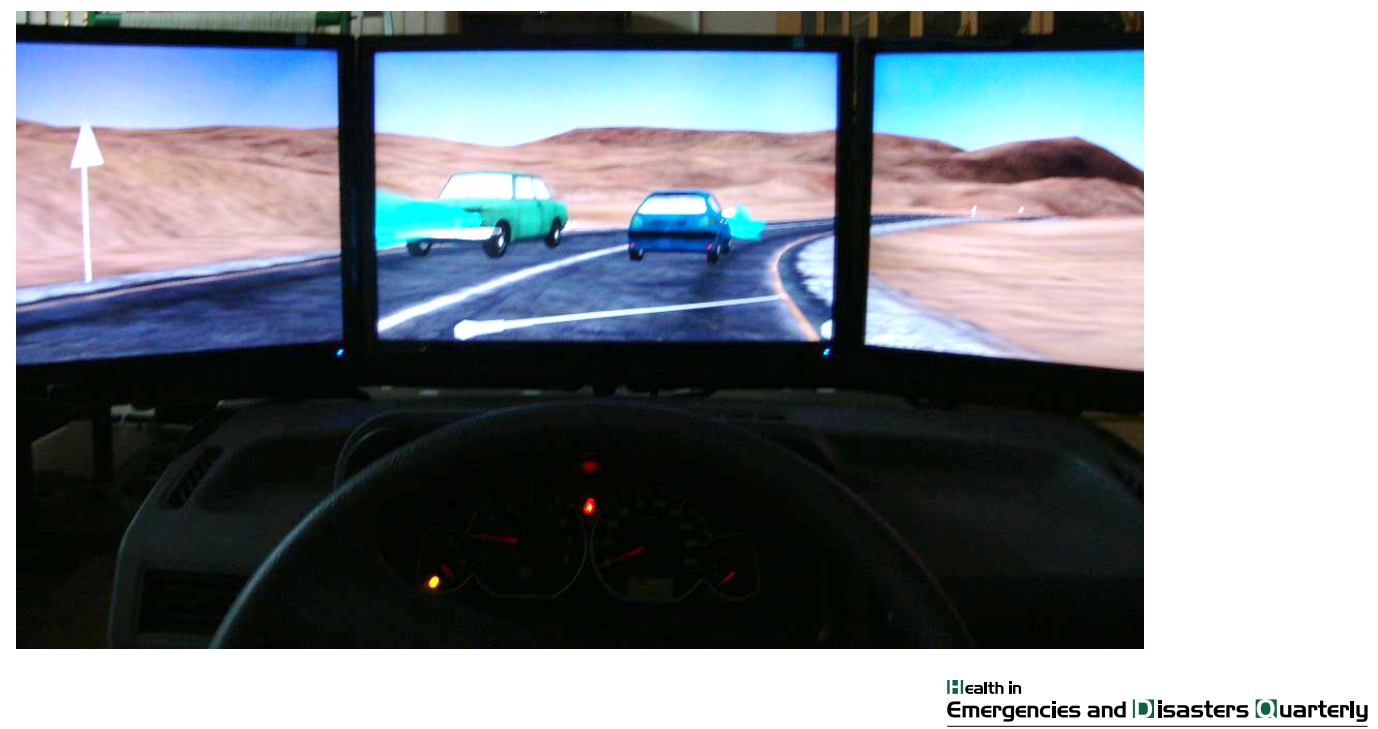

Figure 1. A sample of driving environment roads during the day, using a driving model

the drivers' reactions while driving. Three 19-inch LCD monitors with an angle vision of $120^{\circ}$ are used to show the assimilated environment to the driver panoramically, and the natural sounds and noises of the car are playing using two speakers and headsets. This simulator updates the input and output data 90 times per second. It is also able to simulate driving situations both during day and night and measure and record the time of releasing the gas pedal and applying the brake in accordance with the front car's brake (Figure 1). This simulator works like an instrument in the Virtual Reality Laboratory of Khajeh Nasir Toosi University of Technology [19, 21]. The simulator is kept at room temperature and an audio-control and quiet room.

\section{Study procedure}

Each participant was asked to drive in a 2-way road for $60 \mathrm{~min}$. There were some assimilated cars on the road that moved in the same direction, causing the driver to apply a brake or stop the car randomly. Flashing or standard brake lights were used in these cars and the participant should react to the situation as well. The driving system records the time of the driver's reaction and makes the analyses possible. Each participant using a driving simulator system drove for an hour in the day and night conditions, during which, according to the protocol, the driver was randomly exposed to the standard and flashing brake lights $(7 \mathrm{~Hz})$.

The data obtained from driving tests, including reaction times, were recorded by the simulator software and were analyzed in SPSS V. 16. The simultaneous effect of independent variables on the time of reaction against braking and releasing the gas pedal were studied using a linear mixed model. Independent parameters, such as fixed effect input to the model were age, sex (female $=0$, male=1), education (high school diploma $=0$, technicians $=1, \mathrm{BA} / \mathrm{BS}=2, \mathrm{MA} / \mathrm{MS}=3, \mathrm{PhD}=4)$, a history of playing video driving game $(\mathrm{no}=0$, yes $=1)$, the year of taking driving license, driving experience (beginner $=0$, novice $=1$, experienced $=2$ ), driving condition $($ day $=0$, night=1), time to collision (ms) and the brake light type (standard $=0$, flashing $=1$ ). The random parameter for the mixed model was ID (driver brake observation).

\section{Results}

Four drivers ( 3 women and 1 man) could not finish the experiment, as the result of some problems related to the simulator sicknesses (such as being out of focus, sore eyes, dizziness, nausea, etc.) and were asked to leave the experiment for their safety [23]. The Mean \pm SD age of the remaining 46 participants was $30.37 \pm 6.644$ years, including 10 women with the Mean \pm SD age of $29 \pm 4.784$ years and 36 men with the Mean \pm SD age of $30.75 \pm 7.085$ years. Among the participants, $54.35 \%$ had a history of playing computer driving games. Regarding the educational level, 14 subjects had a high school diploma, 5 subjects were technicians, 10 subjects had a BA/BS degree, 15 subjects had an MA/MS degree, and 2 participants had $\mathrm{PhD}$ degree. The mean time elapsed since taking a second-class driving license was 7.37 years. Among the participants, there were 4 novice drivers, 13 beginner drivers, and 29 experienced drivers. Tables 1 and Tables 2 show the effects of independent variables on brake reaction time and releasing the gas pedal. 
Table 1. Estimates of the fixed effects on brake reaction time and the final mixed model analysis output

\begin{tabular}{|c|c|c|c|c|c|c|}
\hline & Parameter & Estimate (ms) & Std. Error & df & $\mathbf{t}$ & Sig. \\
\hline Age & - & -11.58 & 2.96 & 2396 & -3.910 & $<0.000$ \\
\hline Sex & Female (ref. male) & 75.52 & 31.88 & 2396 & 2.369 & 0.018 \\
\hline \multirow{4}{*}{ Education } & Technicians (ref. high school diploma) & -103.91 & 40.31 & 2396 & -2.578 & 0.010 \\
\hline & BA/BS (ref. high school diploma) & -146.26 & 39.65 & 2396 & -3.689 & $<0.000$ \\
\hline & MA/MS (ref. high school diploma) & -175.24 & 34.73 & 2396 & -5.046 & $<0.000$ \\
\hline & PhD (ref. high school diploma) & -24.60 & 65.54 & 2396 & -0.375 & 0.707 \\
\hline Video games & No (ref. yes) & 81.26 & 25.79 & 2396 & 3.151 & 0.002 \\
\hline Taking driving license (y) & - & 8.18 & 3.78 & 2396 & 2.161 & 0.031 \\
\hline \multirow{2}{*}{ Driving experience } & Novice (ref. beginner) & -267.66 & 45.01 & 2396 & -5.946 & $<0.001$ \\
\hline & Experienced (ref. beginner) & -177.08 & 51.21 & 2396 & -3.458 & 0.001 \\
\hline Time to collision (ms) & - & 0.26 & 0.01 & 2396 & 30.040 & $<0.001$ \\
\hline Brake light & Standard (ref. flashing) & 323.42 & 21.62 & 2396 & $<0.001$ & $<0.001$ \\
\hline
\end{tabular}

An increase in the driver's age results in a decrease of $11.58 \mathrm{~ms}$ in his reaction brake time $(\mathrm{P}<0.001)$. Compared with men, brake reaction time in women was $72.52 \mathrm{~ms}$ more than men $(\mathrm{P}=0.018)$. The drivers' reaction who had a history of playing driving video games, was $81.26 \mathrm{~ms}$ quicker $(\mathrm{P}=0.002)$. By increasing the time elapsed since taking a driving license, brake reaction time $(8.18 \mathrm{~ms})$ also increased $(\mathrm{P}=0.031)$. Comparing the beginner and novice drivers, the former group showed a quicker reaction time $(-267.66 \mathrm{~ms})$ to apply the brakes $(\mathrm{P}<0.001)$, and comparing the beginner and experienced groups in a similar situation, the experienced group applied the brakes quickly $(-177.08 \mathrm{~ms} ; \mathrm{P}=0.001)$. According to the linear mixed model used for data analysis (Tables 1
$\&$ Tables 2), one of the most effective factors on brake reaction time and release gas pedal time was the time to collision $(\mathrm{P}<0.001)$. Speed, the distance between two cars, brake velocity, and acceleration of the front vehicle are the main factors affecting the time to collision. Using flashing brake lights improved braking reaction time (323.42 ms; $\mathrm{P}<0.001$ ).

As shown in Figure 2, the mean brake reaction time in women was more than men (252.75 versus $214.23 \mathrm{~ms}$ ) using standard and flashing brake lights. The mean brake reaction time in women and men using the standard and flashing brake lights were 1366 and $946.21 \mathrm{~ms}$, and 1113.25 and $731.98 \mathrm{~ms}$, respectively.

Table 2. Estimates of the fixed effects on releasing gas pedal time, final mixed model analysis output

\begin{tabular}{|c|c|c|c|c|c|c|}
\hline & Parameter & Estimate (ms) & Std. Error & df & $\mathbf{t}$ & Sig. \\
\hline \multirow{5}{*}{ Education } & Technicians (ref. high school diploma) & -59.09 & 34.28 & 2955 & -1.724 & 0.085 \\
\hline & BA/BS (ref. high school diploma) & -136.20 & 29.59 & 2955 & -4.603 & $<0.000$ \\
\hline & & & & & & \\
\hline & MA/MS (ref. high school diploma) & -83.60 & 27.24 & 2955 & -3.069 & 0.002 \\
\hline & PhD (ref. high school diploma) & -138.10 & 58.92 & 2955 & -2.344 & 0.019 \\
\hline Time to collision (ms) & - & 0.08 & 0.01 & 2955 & 11.796 & $<0.000$ \\
\hline Brake light & Standard (ref. flashing) & 50.22 & 21.00 & 2955 & 2.391 & 0.017 \\
\hline
\end{tabular}




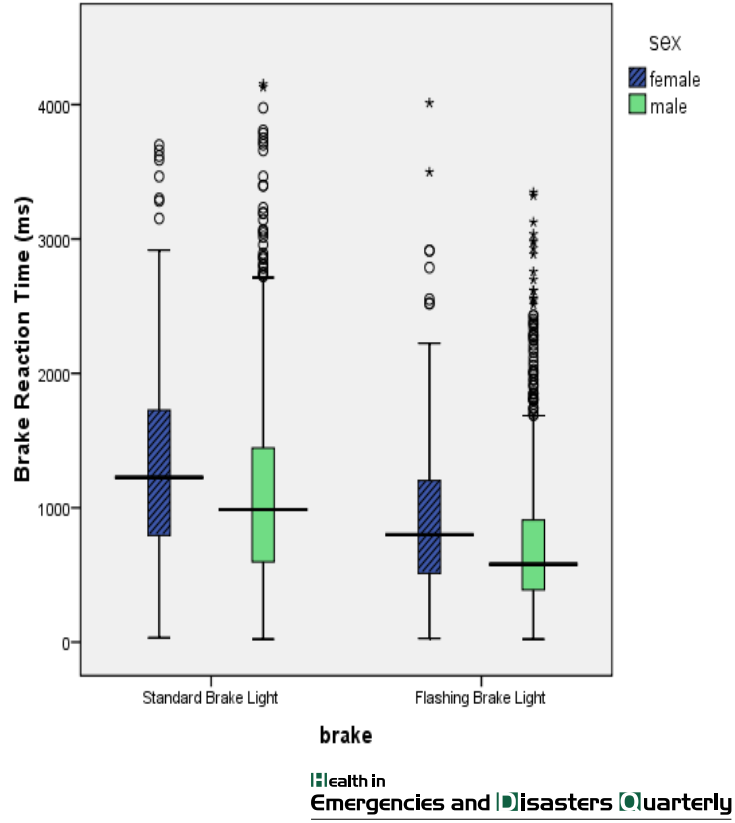

Figure 2. Differences in brake reaction time between men and women using the standard and flashing brake lights

Figure 3 shows the differences in brake reaction time in three experience levels of driving using the standard and flashing brake lights. The mean brake reaction time of the beginner, novice, and experienced drivers was 1318.64, 976.36, and $951.19 \mathrm{~ms}$, respectively. Using flashing brake lights decreased the time of releasing gas pedal by $50.22 \mathrm{~ms}(\mathrm{P}=0.017)$.

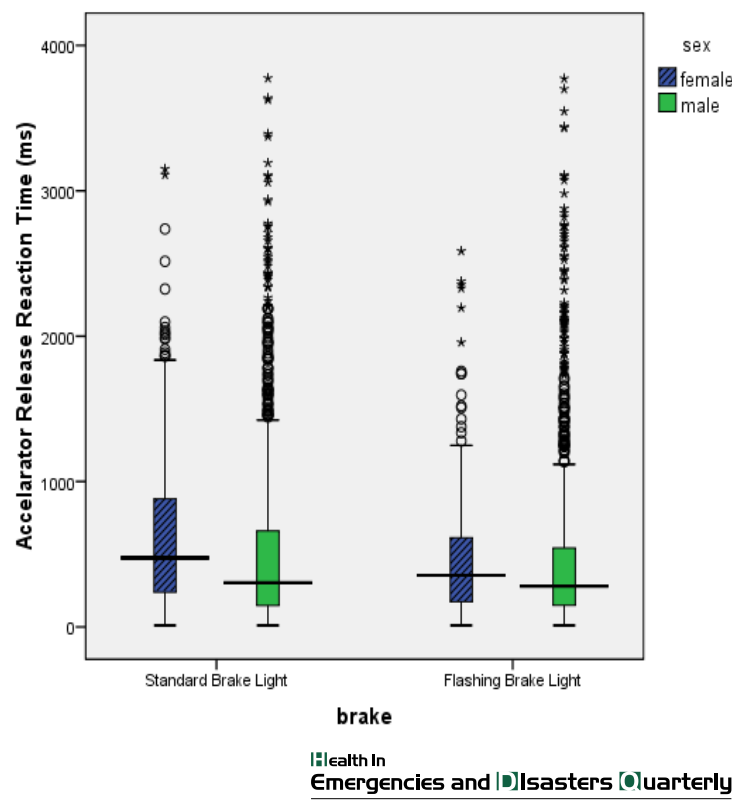

Figure 4. Different times of the reaction to release gas pedal between men and women using the standard and blinking lights

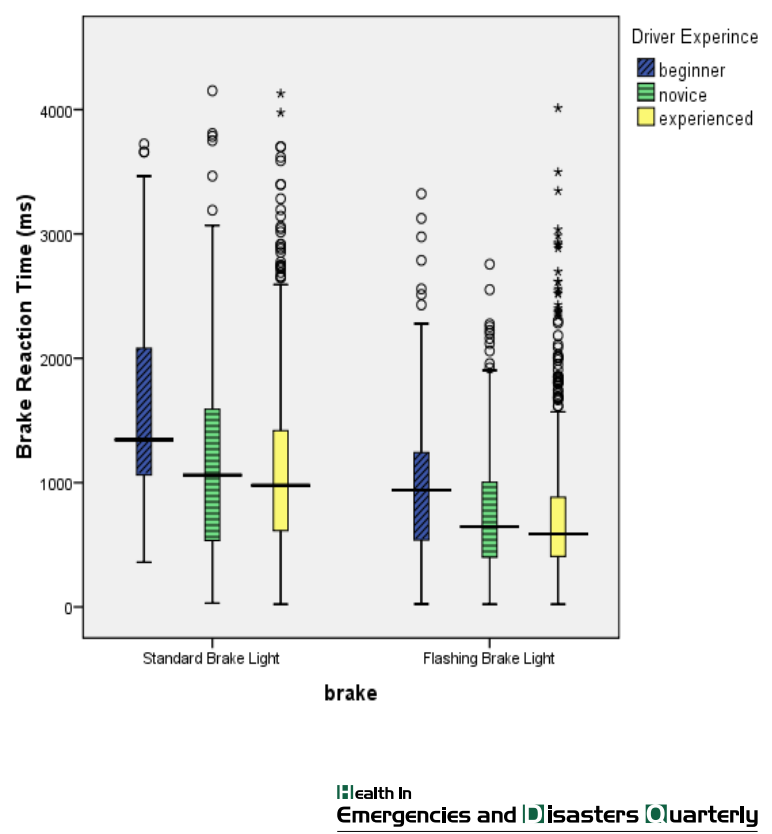

Figure 3. The difference in brake reaction time based on driving experience, using the standard and flashing brake lights

The time of releasing gas pedal between men and women is shown in Figure 4 using the standard and flashing brake lights. The mean time of releasing gas pedal in females using the standard and flashing brake lights was 641.78 and $483.28 \mathrm{~ms}$, respectively. Besides, the mean time of releasing gas pedal in males using the standard and flashing brake lights was 523.17 and $478.53 \mathrm{~ms}$, respectively. Day and night driving showed no significant effect on brake reaction time $(\mathrm{P}>0.05)$.

\section{Discussion}

The results showed a significant correlation between the drivers' age and brake reaction time. By increasing the age of the driver, a significant decrease in brake reaction time is observed $(11.58 \mathrm{~ms})$. Therefore, older drivers have a shorter brake reaction time. It should be mentioned that the age range of the subjects in the present study was 20-46 years, which varies from the young to older adults. However, Makishita et al. [24], Martin et al. [25], and Shinar et al. [26] have reported a significant difference between the brake reaction time in young and older drivers, where older adults showed slower reactions. Our results showed a significant difference in brake reaction time between men and women (75.52 $\mathrm{ms}$ ), which proves the gender differences in brake reaction time. Sylvak et al. and Consiglo et al. reported no relationship between gender and brake reaction time [27, 28]. However, Mahmood and Asa reported that women had slower brake reaction time [29]. 
By increasing the time elapsed since taking the driving license, braking reaction time improved. Therefore, an increase of $8.17 \mathrm{~ms}$ was seen in the reaction time per year elapsed since taking a driving license. This finding contrasts with the results reported by Sagberg and Bjørnskau [10] and Rosenbloom [30]. Using different reaction time measurement tools can be a reason for this difference. In the present study, the driving simulator system recorded the driver's reaction time; however, Sagberg and Bjørnskau used a video-based system and asked participants to push a bottom as they felt the danger and then recorded their time of reaction using a computer. It is believed that using a driving simulator resembles the real driving situations, similar to the present study.

Although driving experience was not considered as a significant factor affecting the reaction time to release the gas pedal, it plays a vital role in stopping the car $(\mathrm{P}=0.001)$. According to Figure 3, the more experienced had a shorter and quicker brake reaction time while driving. These results are not consistent with the results reported by Somala et al. (1998). Although Somala applied regular cars (Lada and Mitsubishi) in a real environment, the gender difference (Somala study: 20 women and 8 men versus the present study: 10 women and 36 men) and different driving experiences ( 6 beginners, 13 novices and 9 experienced drivers in Somala study versus 4 beginners, 13 novices and 29 experienced drivers in the present study) can be regarded as the reasons for observing different results. In the present study, samples were more experienced in driving, whereas in Somala study, they were novice or beginner drivers [22]. The mean time to release gas pedal while driving during the day was less than that of driving at night; however, day and night driving showed no significant effect on drivers' reactions. This finding is consistent with the results reported by Isler and Starki [11] and Brooks and Rafat studies [12].

The main finding of the current study was the significant effect of the type of brake light on the driver's reaction, which is in line with the results of Isler and Starki, Berg et al. Alfredick, Lee and Milgram, and Tang et al. $[11,14,17,31]$.

Several studies have investigated the leading causes of accidents. Studying the effective factors, they aimed at preventing accidents and, as a result, saving human lives and reducing financial costs [20]. In this regard, in the present study, the flashing brake lights were used to decrease the driver's brake reaction time and prevent the rear-end collisions. By using flashing brake lights with a frequency of $7 \mathrm{~Hz}$, the brake reaction time decreased
$323.42 \mathrm{~ms}$. The findings of our study can help reduce the number of future accidents.

\section{Conclusion}

This study was done to determine the effect of a flashing brake light on the driver's reactive behaviors in a simulator environment and demonstrated the positive impact of this design on the driver's length of reaction. More studies are suggested to be done in the simulation environment as well as in field studies to confirm this conclusion.

\section{Ethical Considerations}

\section{Compliance with ethical guidelines}

There was no ethical considerations to be considered in this research.

\section{Funding}

The Hamadan University of Medical Sciences funded this study.

\section{Conflict of interest}

There is no conflict of interest.

\section{References}

[1] World Health Organization. Global status report on road safety: Time for action. Geneva,: World Health Organization; 2009.

[2] Bhalla K, Naghavi M, Shahraz S, Bartels D, Murray CJL. Building national estimates of the burden of road traffic injuries in developing countries from all available data sources: Iran. Injury Prevention. 2009; 15(3):150-6. [DOI:10.1136/ ip.2008.020826] [PMID]

[3] Javadi S-M-H, Tahmasebi S, Azari-Arghun T, Arshi M, Alipour F. The youth and experience of traffic accidents (grounded theory). Health in Emergencies and Disasters Quarterly. 2017; 2(2):79-88. [DOI:10.18869/nrip.hdq.2.2.79]

[4] Saei A, Rahmani A, Ebadi A, Khankeh HR. Driver's effective factors in traffic accident: A sequential explanatory mixed methods. Health in Emergencies and Disasters Quarterly. 2017; 3(1):31-8. [DOI:10.29252/nrip.hdq.3.1.31]

[5] Iranian Legal Medicine Organization. [Death and injuries resulting from traffic accidents 2009 (persian)]. Tehran: Iranian Legal Medicine Organization; 2010.

[6] Matsubayashi K, Yamada Y, Iyoda M, Koike S, Kawasaki T, Tokuda M. Development of rear pre-crash safety system 
for rear-end collisions. Bunkyo: Toyota Motor Corporation Japan; 2007.

[7] Ho C, Spence C. The multisensory driver: Implications for ergonomic car interface design. Boca Raton: CRC Press; 2017.

[8] Regan MA, Lee JD, Young K. Driver distraction: Theory, effects, and mitigation. Boca Raton: CRC Press; 2008.

[9] Castro C. Human factors of visual and cognitive performance in driving. Boca Raton: CRC Press; 2009. [DOI:10.1201/9781420055337]

[10] Sagberg F, Bjørnskau T. Hazard perception and driving experience among novice drivers. Accident Analysis and Prevention. 2006; 38(2):407-14. [DOI:10.1016/j.aap.2005.10.014] [PMID]

[11] Isler RB, Starkey NJ. Evaluation of a sudden brake warning system: Effect on the response time of the following driver. Applied Ergonomics. 2010; 41(4):569-76. [DOI:10.1016/j.apergo.2009.12.002] [PMID]

[12] Brooks KR, Rafat ME. Simulation of driving in low-visibility conditions: Does stereopsis improve speed perception? Perception. 2015; 44(2):145-56. [DOI:10.1068/p7779] [PMID]

[13] Bridger R. Introduction to ergonomics. Boca Raton: CRC Press; 2008.

[14] Li Z, Milgram P. An empirical investigation of a dynamic brake light concept for reduction of rear-end collision accidents during emergency braking. Human Factors and Ergonomics Society. 2005; 49 (22):1940-4. [DOI:10.1177/15419312 0504902212]

[15] Ho C, Reed N, Spence C. Assessing the effectiveness of "intuitive" vibrotactile warning signals in preventing front-to-rear-end collisions in a driving simulator. Accident Analysis \& Prevention. 2006; 38(5):988-96. [DOI:10.1016/j. aap.2006.04.002] [PMID]

[16] Scott JJ. A Comparison of Tactile, Visual, and Auditory Warnings for Rear-End Collision Prevention in Simulated Driving. The Journal of the Human Factors and Ergonomics Society. 2008; 5(2):264-75. [DOI:10.1518/001872008X250674] [PMID]

[17] Alferdinck JW. Evaluation of Emergency Brake Light Display (EBLD) systems. Soesterberg: TNO report; 2004.

[18] Khammar A, Moghimian M, Ebrahimi MH, Abbasi M, Baneshi MM, Yari AR, et al. Effects of bright light shock on sleepiness and adaptation among night workers of a hospital in Iran. Annals of Tropical Medicine and Public Health. 2017; 10(3):595-9.

[19] Poursadeghiyan M, Mazloumi A, Saraji GN, Niknezhad A, Akbarzadeh A, Ebrahimi MH. Determination the levels of subjective and observer rating of drowsiness and their associations with facial dynamic changes. Iranian Journal of Public Health. 2017; 46(1):93-102.

[20] Taheri SM, Matsushita K, Sasaki M. Virtual reality driving simulation for measuring driver behavior and characteristics. Journal of transportation technologies. 2017; 7(2):123-32. [DOI:10.4236/jtts.2017.72009]

[21] Poursadeghiyan M, Mazloumi A, Saraji GN, Baneshi MM, Khammar A, Ebrahimi MH. Using image processing in the proposed drowsiness detection system design. Iranian Journal of Public Health. 2018; 47(9):1371-8.

[22] Summala H, Lamble D, Laakso M. Driving Experience And Perception Of The Lead Car's Braking When Looking At In-Car Targets. Accident Analysis and Prevention. 1998; 30(4):401-7. [DOI:10.1016/S0001-4575(98)00005-0]

[23] Brooks JO, Goodenough RR, Crisler MC, Klein ND, Alley RL, Koon BL, et al. Simulator sickness during driving simulation studies. Accident Analysis and Prevention. 2010; 42(3):788-96. [DOI:10.1016/j.aap.2009.04.013] [PMID]

[24] Makishita H, Matsunaga K. Differences of drivers' reaction times according to age and mental workload. Accident Analysis and Prevention. 2008; 40(2):567-75. [DOI:10.1016/j. aap.2007.08.012] [PMID]

[25] Martin PL, Audeta T, Corriveaua H, Hamel M, D'Amours $\mathrm{M}$, Smeesters C. Comparison between younger and older drivers of the effect of obstacle direction on the minimum obstacle distance to brake and avoid a motor vehicle accident. Accident Analysis \& Prevention. 2010; 42(4):1144-50 [DOI:10.1016/j.aap.2010.01.001] [PMID]

[26] Shinar D, Tractinsky N, Compton R. Effects of practice, age, and task demands, on interference from a phone task while driving. Accident Analysis \& Prevention. 2005; 37(2):315-26 [DOI:10.1016/j.aap.2004.09.007] [PMID]

[27] Sivak M, Flannagan MJ, Sato T, Traube EC, Aoki M. Reaction Times To NEON, LED, And Fast Incandescent Brake Lamps. Michigan: Transportation Research Institute, 1994; 37(6):989-94. [DOI:10.1080/00140139408963712] [PMID]

[28] Consiglio W, Driscoll P, Witte M, Berg WP. Effect of cellular telephone conversations and other potential interference on reaction time in a braking response. Accident Analysis \& Prevention. 2003; 35(4):495-500 [DOI:10.1016/ S0001-4575(02)00027-1]

[29] Mehmood A, Easa SM. Modeling Reaction Time in CarFollowing Behaviour Based on Human Factors. International Journal of Applied Science, Engineering and Technology. 2009; 3(9):1-9.

[30] Rosenbloom T, Perlman A, Pereg A. Hazard perception of motorcyclists and car drivers. Accident Analysis and Prevention. 2011; 43(3):601-4. [DOI:10.1016/j.aap.2010.08.005] [PMID]

[31] Berg WP, D. E, Berglund b, J. A, Strang a, Baum MJ. Attention-capturing properties of high frequency luminance flicker: Implications for brake light conspicuity. Transportation Research. 2007; 10(1):22-32. [DOI:10.1016/j.trf.2006.03.006] 
This Page Intentionally Left Blank 